\title{
International medical graduates (imgs) in Canada and the Netherlands: Can the Dutch learn from Canadian experiences? A survey among academic stakeholders in Canada
}

\author{
Paul Herfs $^{1 *}$ and Shafi Bhuiyan ${ }^{2}$ \\ ${ }^{1}$ European Research Centre on Migration and Ethnic Relations of Utrecht University, The Netherlands \\ ${ }^{2}$ School of Occupational and Public Health, Ryerson University Toronto, Canada
}

\begin{abstract}
Background: International Medical Graduates (non-Canadians with medical degrees obtained outside Northern America) often face challenges in securing employment as medical doctors when entering a new country. By exploring the policy of Canadian authorities in dealing with IMGs, the researchers tried to learn lessons for IMG policies in the Netherlands. In the Spring of 2016 a Dutch researcher specialized in migration of non-European doctors in the Netherlands visited selected medical schools in Canada (Quebec, Ontario, Alberta, British Columbia) and the Medical Council of Canada. The purpose of this visit was to explore the opportunities for International Medical Graduates (IMGs) to continue practice in their medical profession after migration to Canada. Canada is well known for the way it deals with highly skilled migrants. The research question was: What best practices or policies about IMGs in Canada could possibly be adopted by the Netherlands?

Methods and results: Based on interviews and review of the literature, it appeared that IMGs had to compete with Canadians Studying Abroad (Canadians with medical degrees obtained outside Northern America) for residency positions. Canadians Studying Abroad seemed to be in a more favorable position compared to non-Canadian doctors to continue practice in their medical profession after migration.

Conclusion: Alternative programs for IMGs as developed at Ryerson University in Toronto might be a good practice if no other route is available. That practice could be adopted by the Netherlands. IMGs can pursue training, which includes a placement at Ryerson University to become qualified as IT-staff, financial and operational managers in Canadian health care.
\end{abstract}

\begin{abstract}
Abbreviations: CaRMS: Canadian Residency Matching Service, CSA: Canadians Studying Abroad, Canadians who leave Canada for their tertiary or higher education. If Canadians Studying Abroad return to Canada with foreign medical degrees they are considered IMGs, IMGs: International Medical Graduates, foreign trained doctors. IMGs are not necessarily holders of foreign passports, MCCEE: Medical Council of Canada Evaluating Examination, MCCQE: Medical Council of Canada Qualifying Examination, NAC examination: National Assessment Collaboration Examination, OSCE: Objective Structured Clinical Examination, TOEFL: Test of English as a Foreign Language.
\end{abstract}

\section{Background}

International Medical Graduates (IMGs) often face challenges in securing employment when entering a new country. Canada is well known for its positive attitude towards migrants, especially when these migrants are highly skilled. The Netherlands' policy on the contrary, can be characterized as restrictive towards migrants, whether highly skilled or not [1]. International medical graduates in Canada are graduates who obtained a non-North American medical degree. International medical graduates in the Netherlands are those graduates who obtained a non-European Economic Area medical degree. The definition of international medical graduate does not refer to citizenship or legal status in Canada and the Netherlands.
Because of the general positive attitude towards (skilled) migrants in Canada [2] one might assume that IMGs in Canada will have equal opportunities for recognition of their medical degrees and obtaining permission to work as medical doctors. In the Netherlands, where migrants are less welcomed, one might assume that IMGs may face challenges with recognition of their medical degrees and obtaining permission to work as medical doctors. Very few studies have explored opportunities available to IMG newcomers to Canada and the Netherlands. The purpose of this study was to explore experiences of international medical graduates after migration to either Canada or the Netherlands. The research question was: what best practices regarding IMGs in Canada could possibly be transferred to the Netherlands? In order to identify these best practices, Paul Herfs interviewed deans, vice-deans and IMG coordinators at several medical schools throughout Canada.

${ }^{*}$ Correspondence to: Paul Herfs, European Research Centre on Migration and Ethnic Relations of Utrecht University, The Netherlands, E-mail: p.g.p.herfs@uu.nl

Key words: international medical graduates, migrating doctors, highly skilled migrants, assessment procedures

Received: December 19, 2019; Accepted: January 07, 2020; Published: January 10,2020 
Herfs P (2020) International medical graduates (imgs) in Canada and the Netherlands: Can the Dutch learn from Canadian experiences? A survey among academic stakeholders in Canada

The Dutch assessment procedure was introduced in 2005. After a delegation visited the United States in order to study the US assessment process, the Dutch Department of Health wanted to adopt the United States Medical Licensing Examinations (USMLE). This idea has been abandoned due to the expected exclusion of Dutch refugees with Islamic backgrounds from certain middle eastern countries post-911. The Dutch assessment procedure is quite similar to the USMLE.

\section{Methods}

Stakeholders, mostly deans and vice deans, in Canadian medical schools ( 2 medical schools had French as language of instruction; 4 had English as language of instruction) were interviewed to explore options available to IMGs entering Canada who wish to practice as physicians in Canada. We made use of a semi structured questionnaire.

The following questions were presented to the interviewees.

- Canada is well known for its intentions to acknowledge foreign credentials. Is this true for International Medical Graduates?

- I know that IMG's have to participate in an assessment procedure. What will happen if the mastery of the French or English language of an IMG is not sufficient?

- Do you know where most IMGs come from?

- And do you know what their background is? Are they refugees, are they partners of Canadian citizens? Or ...?

- Are there advisors from medical schools or elsewhere to provide IMGs with relevant information on their situation in Canada?

- Is there is a possibility to take training programs (English language and medical programs) in order to prepare on the assessment procedure?

- Is it costly to take preparatory programs?

- I learned that after obtaining recognition of the equivalence of their degrees from the Collège des Médecins du Québec IMGs have to meet the requirements to apply for a postdoctoral university training program. I a report I obtained dated 2010 it was described that admission to postdoctoral university training programs was very problematic. Do you know why IMGs are not admitted to postdoctoral training programs in spite of shortages?

- Recently these results were again reported. What are the motives of the four medical schools not to grant training programs for IMGs?

- I know there are several pathways to become a MD in Canada. Some get recognition of their medical degree. Others would return to a medical school to do 2 years clerkship. What would you advise an IMG?

- Is the pathway of clerkship a better guarantee for an IMG to have a residency position later than passing the medical knowledge examinations? Would you advise an IMG to take the route of the clerkship? Is that route accessible and not too expensive?

- Have you any idea how long it will take an IMG to finish procedures of admission? How can they survive in the meantime if they don't have an income?

During the interviews the answers were described directly in protocols. Afterwards the outcomes were analyzed per question.

In the Netherlands information about practice opportunities available to IMGs was gathered through key informants at the Department of Health and the experiences of IMG members of the
Dutch Association of Foreign Medical Doctors (in Dutch: Vereniging van Buitenlands Gediplomeerde Artsen).

\section{Procedures of recognition}

In Canada there are several licensing procedures for foreign medical doctors, as the ten provinces and three territories had each developed their own assessment Procedures.

We will not describe all different procedures. We choose to briefly concentrate on describing the procedures in Ontario and British Columbia, the provinces where most IMGs settle [3].

Currently, all IMGs have to pass the Medical Council of Canada Evaluating Examination (MCCEE) and the National Assessment Collaboration Examination (NAC) and in British Columbia also the Objective Structured Clinical Examination (OSCE) to be eligible to apply for an IMG stream residency position in Canada through the first iteration of the Canadian Residency Matching Service (CaRMS) match. The Medical Council of Canada website, stipulate that "As of 2019, IMGs will no longer be required to pass the MCCEE before taking the Medical Council of Canada Qualifying Examination (MCCQE Part I) or the NAC Examination" [4]. This implies that IMGs will be able to directly take an examination (MCCQE Part I) that is more complex and includes content that specifically assesses knowledge and clinical decision-making related to practicing medicine in Canada.

As stated previously, each province has its own licensing procedures. The province of Ontario, for example, also requires Canadian citizenship, or proof of permanent residency or authorization to work. In addition, proof of mastery of the English language must be demonstrated by achieving a specified minimum score on the Test of English as a Foreign Language (TOEFL).

An IMG who passes the MCCEE and the NAC examination and who meets the above mentioned criteria can apply to the Canadian Residency Matching Service (CaRMS) through the Postgraduate Year 1 (PGY1) pathway. The competition to secure a residency position is very rigorous. Selection is based on high scores on the Medical Council of Canada exams, past performance in medical school, excellent communication skills (verbal and written), professional practice experience and an interview. About 1,500 IMGs apply for the approximately $200 \mathrm{IMG}$ stream residency positions at the (6) Ontario medical schools [5].

In British Columbia the procedure is as follows. After meeting residency requirements, as well as demonstrating proficiency in the English language, IMGs are required to take the Medical Council of Canada Evaluating Examination (MCCEE) and the National Assessment Collaboration (NAC) Examination in order to demonstrate that basic medical and clinical knowledge is sufficient. This test is then followed by a six hour Objective Structured Clinical Examination (OSCE), during which the IMGs take case histories and perform physical examinations and have their doctor-patient communication skills assessed. Finally, their medical and clinical skills, as well as the way they work together in a multi-disciplinary team, are evaluated during a practical working period of 6 weeks [6,7].

\section{Results}

Through our interviews with staff members of medical schools in Quebec, Ontario, Alberta and British Columbia, it became apparent that postgraduate positions are very difficult to access for immigrant International Medical Graduates. The reason behind this seems at 
least partially due to a large number of Canadian students - so-called Canadians Studying Abroad (CSAs) - who leave Canada in order to study medicine abroad in Great Britain, Ireland, Australia and the Caribbean. After completing their medical studies abroad they return - as IMGs - to Canada to compete with immigrant IMGs for residency positions in Canada.

Due to their educational background, skilled workers like IMGs are often favored by the department of immigration. However, after securing permanent residency, IMGs often face barriers to recognition of credentials and securing a CaRMS residency position. Interviewees identified that IMGs are often faced with an ambiguous position between federal and provincial authorities. A skill based merit system is still in place for choosing immigrants by the federal Canadian government. However, on a provincial level immigrant IMGs have to compete with CSAs for the few coveted IMG stream residency positions.

One of the deans reported that in order for an IMG to be successful in the competition for residency positions, the IMG should preferably have obtained his or her medical degree fewer than four years ago. Other medical schools reported that residency positions have been offered to candidates even if an IMG has been out of practice for more than 4 years. IMGs are informed about starting the procedure of assessment and recognition of credentials before coming to Canada. This procedure may take up to 18 months and can be accomplished from a foreign country.

Preparation courses for the assessment procedure are available. Information about these courses can be found on the website of the Canadian Medical Council. These courses are quite costly; some of these courses cost as much as 5,000 Canadian dollars per week. The preparation courses are not offered by Medical Schools.

Those IMGs who do not succeed in securing residency positions can try to obtain a position in under serviced areas e.g. rural British Columbia and Newfoundland. For these under serviced areas the process is less stringent. Between 70 and $80 \%$ of the medical practitioners in these under serviced areas are IMGs.

The assumption that Canada is a country where highly skilled migrants are welcomed does not necessarily apply to International Medical Graduates with foreign passports. All the academic leaders of the medical schools who were interviewed shared this conclusion.

How does information in the literature on IMGs in Canada compare to the findings of the interviews?

In 2010 more than 4,000 Canadians obtained a medical degree outside North America [8].

After completing their medical studies in Europe, Australia and the Caribbean, the majority of these candidates return to Canada with the intention of securing a residency position at one of the medical schools. The CSAs are often perceived to be favored in the selection process [9].

Ontario is probably the province with the highest number of IMGs. Lofters, et al. [3] estimates the current number of IMGs in Ontario to be as high as 6,000 . Of these 6,000 IMGs, approximately 1,500 applicants compete for the maximum 200 residency positions allocated at several medical schools yearly. Obtaining a residency position at a medical school is a highly competitive process complicated further by immigrant IMGs competing with Canadians Studying Abroad (CSA).

A study by MacLellan, et al. [10] showed that IMGs who first completed a full clinical clerkship were more successful in a postgraduate medical training position (residency) than when starting at a residency level. This outcome matches findings in the Netherlands where most IMGs had to take additional medical training and clerkships until 2005 [7]. However, at most medical schools in Canada it is not possible for IMGs to enroll as medical students and complete full clinical clerkships any longer.

Schabort [11,12] conducted surveys of IMGs about the numerous barriers female IMGs faced after arriving in Canada. Although many of them thought that the route that would lead to certification would be manageable - as there was a shortage of physicians in Canada - it appeared that the list of barriers was long. IMGs experience disorientation, they often start at a later stage in their life with their residency than Canadian doctors, IMGs feel disconnected from the educational system and IMGs often have cultural backgrounds that makes it challenging to compete with non-migrants.

In Canada bridging programs are seen as effective facilitators to professional integration. These programs serve several purposes, from education and skills assessment to familiarizing IMGs with the social and cultural context of the Canadian health care system.

\section{Conclusions and discussion}

Unlike Canada, the Netherlands is not an immigration country. Despite that, about $12 \%$ of its population has a non-western background. The attitude towards migration as well as legislation proves restrictive [1]. Canada, in turn, is widely known as a country of immigrants.

It has an open attitude towards migrants, especially highly skilled migrants [2]. The findings obtained through interviews conducted with academic leaders at medical schools, demonstrated that IMGs are often not in a favorable position for securing a residency position, as positions are limited and furthermore they have to compete with Canadians Studying Abroad (CSA).The above described situation does not apply to the Netherlands.

In the Netherlands IMGs have to complete an assessment process if they want to practice as medical doctors. Once this is completed, they can apply for available positions. IMGs do not have to compete with Dutch doctors Studying Abroad as these students hardly exist. However, IMGs in the Netherlands will have to compete with Dutch trained doctors and EU-trained doctors when entering the labor market. No residency positions in the Netherlands are exclusively IMG-earmarked.

The initiative of Dr. S. Bhuiyan from Ryerson University in Toronto, a Canadian good practice, shows promise for adoption in the Netherlands. Ryerson University offers non-licensed healthcare training programs aimed at IMGs who fail to secure a license and/or residency. For some IMGs the assessment process is not accessible for a variety of reasons: language requirements, prohibitive costs, limited time available for exam preparation, deterioration in medical knowledge or skills due to lack of possibilities to practice. A program similar to that developed by Dr. S. Bhuiyan could potentially be of use to those IMGs who will no longer aspire to positions as medical doctors. They can explore positions as IT-staff, financial and operational managers in Dutch health care.

Bridging programs are seen as potential effective transitions to professional integration in Canadian health care. In the Netherlands bridging programs other than language courses for IMGs do not exist [13]. The Netherlands should consider offering bridging programs in order to facilitate the requalification of IMGs (most of them partners of Dutch citizens) as medical doctors. 
Bridging programs for IMGs should be offered to assist IMGs to continue on a medically-related career path given that the evidence demonstrates how difficult it is for a 'foreign trained' physician, regardless of how capable and well-qualified, to practice in the Netherlands and Canada.

Information regarding citizenship and the extensive and highly competitive nature of the process for requalification as medical doctors should be readily available and transparent before IMGs enter Canada or the Netherlands.

Information regarding application for residency and citizenship as well as recognition of foreign medical degrees should ideally be distributed by one agency responsible for the integration of migrants.

If at some point it becomes obvious to IMGs that they will not succeed in the continuation of their medical career, it is advisable to offer IMGs an alternative pathway in which they can use their medical background to pursue a related career.

\section{Ethical approval and consent to participate}

Not applicable.

\section{Consent for publication}

Not applicable.

\section{Competing interests}

The authors report no competing interests.

\section{Availability of data}

Data that support the findings of this study are available from the first author but restrictions apply to the availability of these data, which were used under license for the current study, and so are not publicly available. Data are however available from the authors upon reasonable request.

\section{Author's contributions}

All authors contributed to the article. They read and approved the final manuscript.

\section{Funding}

This study did not receive any funds from any funding body. The authors were not paid for their research contributions.

\section{Acknowledgements}

We wish to express our appreciation to prof. dr. John de Wit (Faculty of Social Sciences; Utrecht University; The Netherlands) for his valuable comments on the draft version of this article. We also wish to express our great appreciation to dr. I. Schabort (Associate Professor and International Medical Graduate Coordinator in the Department of Family Medicine at McMaster University) for her valuable comments on earlier drafts of this article.

\section{References}

1. Wetenschappelijk Onderzoek- en Documentatiecentrum (2015) How (un)restrictive are we? 'Adjusted' and 'expected' asylum recognition rates in Europe. Ministry of Justice, The Hague, The Netherlands.

2. CBC News (2016) Immigration Minister John McCallum to reveal 'substantially' higher newcomer targets.

3. Lofters A, Slater M, Thulien N (2013) The brain drain: factors influencing physician migration to Canada. Health 5: 125-137.

4. Medical Council of Canada (2017) Assessment Evolution.

5. Thomson G, Cohl K (2011) IMG Selection: Independent review of access to postgraduate programs by international medical graduates in Ontario. Ministry of Health and Longterm Care.

6. Andrew R, Bates J (2000) Program for licensure for international medical graduate in British Columbia: 7 years' experience. Can Med Assoc 162: 801-803. [Crossref]

7. Herfs PGP (2009) Buitenlandse artsen in Nederland. [International Medical Graduates in the Netherlands]. Thesis. Utrecht University, The Netherlands.

8. CaRMS report (2010) Canadian students studying medicine abroad.

9. Bhuiyan SU (2016) Building the capacity of Ontario's health care sector through the integration of internationally trained medical doctors (ITMDs): A preliminary result from a pilot bridging program at Ryerson University. Toronto, Canada.

10. MacLellan AM, Brailovsky C, Miller F, Leboeuf S (2012) Clerkship pathway. Can Fam Physician 58: 662-667.

11. Schabort I (2018) Female international medical graduates. In: Women in Medicine.

12. Schabort I, Mercuri M, Grierson LEM (2014) Predicting international medical graduate success on college certification examinations. Can Fam Physician 60: 478-484. [Crossref]

13. Kramer J (2017) Verspild Talent [Talents spoiled]. Arts en Auto, Utrecht, the Netherlands. 